УДК 343.01

DOI: $10.17223 / 22253513 / 31 / 8$

\title{
С.А. Елисеев
}

\section{РОССИЙСКАЯ ЮРИДИЧЕСКАЯ МЫСЛЬ ПЕРВОЙ ПОЛОВИНЫ ХІХ ВЕКА О ПРЕДМЕТЕ НАУКИ УГОЛОВНОГО ПРАВА}

\begin{abstract}
Рассматриваются взгляды Г. Солнцева, Г. Гордеенко, Я. Баршева, С. Бармева и других российских юристов первой половины XIX в. на предмет науки уголовного права. Показана эволюиия представлений о предназначении науки уголовного права, круге изучаемых ею явлений сочиальной действительности, методах их исследования, роли науки уголовного права в развитии уголовного законодательства, в совершенствовании применения уголовного закона.

Ключевые слова: наука уголовного права, история науки уголовного права, определение и предмет науки уголовного права.
\end{abstract}

Российское уголовное законодательство, как известно, интенсивное развитие получило в первой половине XIX в. (в 1832 г. был издан Свод законов уголовных; в 1845 г. принято Уложение о наказаниях уголовных и исправительных). В это же время стала развиваться и российская наука уголовного права (как ее тогда именовали - наука уголовных законов, или уголовное правоведение, уголовное законоведение). К предмету этой науки в публикациях начала XIX в. относили законы уголовные, или наказательные, а саму науку определяли как «практическое знание истин... из самих законов извлеченных, о неправомерных деяниях граждан, противу общей или частной безопасности устремляемых, и определяющих соразмерные за оные наказания» ${ }^{1}$ [1. С. 2].

В литературе тех лет отмечалось, что в России достижения законодательства далеко опередили успехи науки уголовного правоведения. Так, О. Горегляд писал, что еще нет такого сочинения, которое бы в надлежащем порядке заключало в себе российское уголовное право, задача науки уголовного права - «облегчить обозрение и познание» уголовных законов. Решить эту задачу позволят «приведение в некоторый порядок» всех норм действующего уголовного права, объяснение постепенного их образования [2. C. XXIV-XXV, XXXI]. Поэтому не случайно О. Горегляд посвятил «краткому изложению постепенного образования российских уголовных законов относительно существа оных» почти четвертую часть своей книги; «краткое обозрение истории российского уголовного законодательства и

\footnotetext{
${ }^{1}$ Надо сказать, что в то время термины «наука уголовного правоведения, наука уголовного законоведения» употреблялись и в значении систематического, построенного на общих основаниях изложения знаний об уголовном законе.
} 
правоведения» составило пятую часть труда Г.И. Солнцева. Не оставил без внимания историю уголовных законов России и П. Гуляев ${ }^{1}$ [3. С. I-XI].

В работах тех лет также проводилась мысль, что наука уголовного права не должна ограничиваться исследованием «постановлений положительных законов», она должна изучать «те главные начала, которые служат основанием уголовным законам вообще и должны быть приемлемы в уважение в каждом положительном праве» [4. С. 8].

В те годы наметился и взгляд на науку уголовного права как на науку, изучающую не только юридическую форму, но и социально-психологическое содержание уголовно-правовых категорий. Так, И. Наумов писал: «Чтобы знать разделение преступлений, нужно вникнуть в свойство человека, его обстоятельства и прочее». К точному определению каждого преступления, полагал он, «руководствует» знание побудительных причин к преступлениям; без знания этих причин понятия о преступлениях «бывают смешаны и мера наказания превосходит меру надлежащего» [5. С. 9, 15]. Г.И. Солнцев, рассматривая преступления по «внутреннему или психологическому основанию самого деяния, т.е. по расположению воли и внимания преступника», разделил их на совершенные: 1) с явным намерением, «К нарушению уголовного какого-либо закона предположенным, т.е. по злоумышлению»; 2) без злого намерения, «по одной вине и неосмотрительности преступника без злостного расположения его воли, какую-либо уголовную заповедь нарушающего». Г.И. Солнцев писал, что побудительными причинами злоумышления бывают: непомерные страсти (корыстолюбие, мстительность, излишнее честолюбие, плотское вожделение); заблуждения или превратные о вещах понятия (мнимое сострадание, суеверие, безверие и вообще разврат ума и сердца) [1. С. 78-79]. К причинам преступлений, «по вине или неосторожности производимых», Г.И. Солнцев отнес: «1) нерассудительность и торопливость в суждении; 2) сбивчивость в понятиях об уголовном каком-либо случае или об уголовном законе, оной определяющем; 3) неопытность в производстве дел со стороны судящих и вообще слабые душевные способности» [Там же. С. 78-79, 83].

Представление о науке уголовного права как о науке, изучающей уголовные законы как сохраняющее преемственность подвижное социальное явление, выражающее реалии того или иного времени, получило дальнейшее развитие в публикациях второй трети XIX в. Так, С. Богородский к предмету науки уголовного законоведения отнес «философию уголовных законов у древних и новых народов», «критический разбор различных систем уголовного законоведения». В последнем он усматривал необходимое условие дальнейших успехов теории уголовных законов [6]. И. Данилович, полагая, что уяснение преступления и наказания как предмета уголовного законоведения достигается лишь в случае, когда эти явления изучаются по

\footnotetext{
1 Уместно отметить, что свои исследования эти авторы ограничивали «внешней» историей российских уголовных законов, общей обрисовкой уголовно-правовых запретов из старых узаконений.
} 
положительным законам, утверждал, что «все периоды человеческой образованности находятся в неразрывной между собой связи и служат взаимным себе дополнением...» «Каждый из них, порознь взятый, - писал он, представляет одну сторону идеи правосудия, которой целостность составляет созерцание множества соединенных периодов» [7. С. 340-341]. Поэтому для образования «уголовной науки», полагал И. Данилович, предпочтительнее обращаться «...к историческим исследованиям» и «извлечению из них начал для уголовных сводов», «нежели отвлеченными философскими мечтами» устанавливать положения уголовного закона [Там же. С. 374].

Г. Гордеенко, отвечая в своей диссертации на вопросы, составляет ли Свод уголовных законов систему уголовного правоведения и совершен ли образованием Свода весь подвиг науки, может ли быть названо ученым уголовным законоведением знание одних догматов уголовного законодательства, отметил, что изданием Собрания и Свода законов положен краеугольный камень науке российского законоведения - определены ее источник, предмет и основные задачи. Однако наука этим еще не создана: «изучать буквальный смысл законов не значит еще изучать самые законы», истинное знание права неразрывно соединено со знанием влияния элементов народной жизни на существо и форму права. Поэтому необходимы еще, писал он, долговременные, обширные, разнообразные исследования, чтобы объяснить и раскрыть отечественное право в полном его бытии, «постигнуть это живое, непрерывно обновляющееся начало народной нравственности» [8. С. 18, 21-23]. К цели правоведения Г. Гордеенко отнес «представление уму человеческому истин законодательства в полном их значении, во взаимной внутренней их связи с самими отношениями жизни, всестороннее объяснение их развития по содержанию и форме, изучение их по происхождению и применению». В составе уголовного законоведения он выделил догматическое, историческое, практическое, философское учения [Там же. С. 20].

В догматическом учении Г. Гордеенко видел начальную степень юридического учения, он определял догматическое учение как познание статей Свода как настоящих положительных форм отечественного уголовного права при помощи грамматических и логических изъяснений [Там же. С. 30-31].

Под историческим учением Г. Гордеенко понимал объяснение развития уголовных догматов права из их жизненных источников. Историческое изучение Свода, писал он, должно «раскрыть и объяснить нам не одни проявления права в различные времена, не одни только внешние разнообразные формы, в коих оно развивалось, но и те самые жизненные начала, которые скрывают в себе зародыш и причину сих явлений... Словом, это учение объяснит нам развитие права из его источников - раскроет его жизнь; тогда догматические положения Свода будут в глазах наших не мертвою буквою, но одушевленными органами практического разума, почерпнутого из опыта веков: мы увидим, откуда вытекает каждое положение, из чего оно образовалось, какая постоянная причина поддерживает его бытие, почему именно оно в том, а не в другом образе, - все это объяснит- 
ся нам не посредством догадочных умозаключений, но самими фактами» [8. С. 36-37].

Под практическим учением Г. Гордеенко понимал изучение практики применения норм уголовного закона. Раскрывая суть этого учения, он отмечал, что «уголовные нормы законодательства», управляя общественными и частными отношениями, в строгом смысле «не всегда составляют безусловное и решительное, а только главное руководительное начало, по указанию которого, как по общим примерам, аналогически выводятся решения для встречающихся случаев... Отсюда явствует необходимость и важность знаний, посредствующих в приложении каждого закона к случаям жизни. Знания сии, почерпаясь из соображения прежних опытов, вошедших в закон, с новыми встречающимися случаями изъясняют его действительное значение и, так сказать, пополняют его сферу новыми наблюдениями...» «Практика всегда была и будет, - утверждал Г. Гордеенко, - пояснительным и даже пополнительным источником действующего права...» ${ }^{1}$ [8. С. 47].

Раскрывая содержание философского учения, Г. Гордеенко отметил, что историческое и практическое изучение догматов Уголовного Свода порознь еще не составляет науки уголовного права. «Нужно еще знать, писал он, - место и значение каждого догмата в существующем правомерном состоянии, как все они, подобно членам организма, образуют одно целое, сливаются между собой, проницают себя взаимно, совокупностью своею обнимают отношения жизни... ибо система права не есть совокупность одних законов или догматов, но должна быть вместе и связью существующих правоотношений; в ней выражается совокупность деятельных жизненных отношений и их правомерных начал... [Там же. С. 75-76]. Существенная задача науки российского уголовного права, полагал Г. Гордеенко, - показать присутствие философского элемента права (всеобщих понятий, определяющих «главное содержание всякого положительного права, главные черты его системы») в отечественном уголовном праве, представить его философско-национальную систему [Там же. С. 88-89].

Догматическое, историческое, практическое и философское изучение положений российского уголовного законодательства, считал он, позволит создать полную систему «ученого уголовного законоведения, наделяющего знанием уголовного права в полном его бытии как составной части жизни

\footnotetext{
${ }^{1}$ Нельзя не заметить, что в диссертации Г. Гордеенко получила развитие мысль А.Н. Радищева о том, что изучение практики применения закона позволит наполнять уголовноправовые запреты содержанием, отвечающим реалиям. А.Н. Радищев в записке «О законоположении», составленной в период его работы в Комиссии по составлению законов в 1801-1802 гг. писал: «Обширнейшие из судебных деяний можно почерпнуть мысли для будущего законоположения, ибо, соображая бывшее за многие годы с тем, что бывает ныне, соображая одинаковые происшествия, бывшие в разные времена, разные об одинаковых происшествиях суждения и различное приложение закона, можно вернейшим образом познать, что закону давало силу или его послабляло действие...» [9].
} 
общества». Для составления «правильной» теории российского уголовного права будет полезным, указывал Г. Гордеенко, знание как иностранного уголовного законодательства (в том числе его истории), так и науки уголовного права зарубежных стран, в частности Германии ${ }^{1}$ [10. С. 25-27, 93].

Я. Баршев к предназначению науки уголовного права отнес постижение существа уголовных законов, процесса их органического образования, значения уголовных законов в жизни народа в ту или иную эпоху, «их соотношения с чувством каждого». Он, в частности, говорил; что законодательство в себе представляет «одну внешнюю систему правил для частных случаев, книгу, в которой обозначаются явления идеи правды или в виде случаев, или как отвлеченные результаты их...» В этой книге не записывается «ни процесс постепенного образования общих правил из частных случаев, ни дух одушевляющий законы, ни степень достоинства их, ни отношение их к особенным обстоятельствам народа, ни те вечные и коренные начала, на которых утверждается каждое законодательство». Поэтому существо науки в области права, в том числе и науки уголовного права, состоит в том, «чтобы отыскать и раскрыть коренные начала правды как в идее, так и во временном и местном проявлении ее... ей предлежит довершить работу над правом и обычая, и практики, и даже самого законодательства, возвести все множество и разнообразие юридических истин, ими собранных, к единству и сознанию, осветить всю сферу права, представить право в чистейшем существе его со всеми его началами» [11. С. 102-103, 106-107].

С. Баршев, размышляя о предмете науки уголовного законоведения, писал: «Преступление и наказание как рождаются из закона, так и определяются законом. Уголовные законы, как все, что развивается в истории, не произвольны, но содержат в себе выражения вечных начал правды и справедливости в той мере и степени, как того требуют временные и местные отношения народа, у которого они действуют» [12. С. 2-3].

Для познания положительных уголовных законов, полагал он, «недостаточно только ознакомиться с их содержанием; необходимо постигнуть самое внутреннее существо их и уразуметь внешнее значение в жизни народа, у которого они действуют... Наука... должна представить возможно полное и вполне отчетливое учение о преступлениях и наказаниях. Посему она не может высказать ни одного положения без объяснений и доказательств и должна восполнить и то, что не могло войти в законодательство, но что необходимо для правильного и основательного понимания существа преступления и наказания». «Истинно научное познание уголовных законов», - резюмировал С. Баршев, должно заключать в себе непременно все три элемента: положительный, исторический и философский. Положительное должно познакомить с настоящим, история свяжет настоящее с

\footnotetext{
${ }^{1}$ Отсылка к немецким законам и науке уголовного права не случайна, в диссертации и лекциях Г. Гордеенко опирался на работы немецких юристов. Так, в общей части своих чтений по уголовному праву Г. Гордеенко придерживался труда Эд. Генке «Handbuch des Criminalrecht», изданного в 1823 г. в Берлине (см.: [10]).
} 
прошедшим, философия вложит душу живую в прошедшее и настоящее... Научное изложение положительного уголовного права, действующего «у известного народа... возможно только в тесной его связи» со всеобщим уголовным правом [12. С. 8-9].

Как видим, к середине XIX в. у российских юристов сложилось представление о науке уголовного права как о науке, изучающей социальную и нравственную обусловленность уголовно-правовых запретов, уголовные законы государства, практику их применения, иностранное уголовное законодательство, опыт его применения, зарубежную уголовно-правовую науку. Оставляя в стороне различия в философских взглядах авторов, отметим, что все они не подвергали сомнению положение о том, что наука уголовного права должна рассматривать уголовное законодательство как динамичное, системное образование, исследовать сущность преступлений, объяснять необходимость и справедливость уголовного наказания. При этом в работах того времени проводилась мысль (в одних - в общих чертах, в других - более или менее обстоятельно), что наука уголовного права не может ограничиваться изучением юридических конструкций тех или иных понятий, изучением преступного деяния и наказания как категорий абстрактных, отвлеченных от реалий; она должна исследовать их как жизненные явления. Изучая практику применения российских уголовных законов, зарубежное уголовное законодательство, наука уголовного права должна содействовать правильному построению уголовного законодательства России. Нельзя не заметить, что эти же идеи лежат в основе и современного взгляда на предмет науки российского уголовного права.

\section{Лuтература}

1. Солнцев Г.И. Российское уголовное право. Казань, 1820 / под ред. и с вступ. ст. о Г.И. Солнцеве Г.С. Фельдштейна. Ярославль, 1907. [4], LXXXII, 219 с.

2. Горегляд Г. Опыт начертания российского уголовного права. СПб., 1815. Ч. 1: О преступлениях и наказаниях вообще. [6], XLI, [11], 168 с.

3. Гуляев П. Российское уголовное право, составленное из государственных законов. СПб., 1833. [6], XV, [1], 17-250 с.

4. Нейман И. Начальные основания уголовного права. СПб., 1814. 75 с.

5. Наумов И. Разделение преступлений против права гражданского и против права уголовного. СПб., $1813.21 \mathrm{c.}$

6. Положения, извлеченные из разсуждения о философии уголовных законов у древних и новых народов, которые с одобрения юридического факультета императорского С.-Петербургского университета защищал публично, для получения степени доктора законоведения, Савва Богородский. Санкт-Петербург, 1835.

7. Данилович И. О ходе уголовного законоведения вообще и преимущественно в Германии // Журнал министерства народного просвещения. 1837. Ч. 14. С. 340-341.

8. Гордеенко Г. В чем должно состоять ученое уголовное законоведение в России в настоящее время : дис. на степень доктора прав. Харьков, 1838. 104 с.

9. Радищев А.Н. О законоположении // Радищев А.Н. Избранные философские и общественно-политические произведения. М., 1952. С. 459-460.

10. Фельдштейн Г.С. Главные течения в истории науки уголовного права в России. М., 2003. 465 c. 
11. О влиянии обычая, практики, законодательства и науки на развитие уголовного, в особенности русского, права : речь, произнесенная в торжественном собрании императорского Санкт-Петербургского университета ординарным профессором, доктором прав Яковом Баршевым февраля 8 дня 1846 года. [Б. м. и г.]

12. Баршев С.И. Взгляд на науку уголовного законоведения. [Б. м. и г.]. 23 с.

Eliseev Sergey A., Tomsk State University (Tomsk, Russian Federation)

\section{RUSSIAN LEGAL THOUGHT OF THE FIRST HALF OF THE 19th CENTURY ABOUT THE SUBJECT OF CRIMINAL LAW}

Keywords: criminal law science, history of criminal law science, definition and subject of criminal law science.

\section{DOI: $10.17223 / 22253513 / 31 / 8$}

Russian criminal legislation, as we know, gained intensive development in the first half of the 19th century (in 1832 the Code of criminal laws was published; in 1845 the Regulations about criminal punishments and correctional ones was adopted). The Russian criminal law science started developing at the same time (then it was called the science of criminal laws or criminal jurisprudence). In the literature of those years it was noted that the achievements in legislation far outstripped the achievements of criminal jurisprudence in Russia; the enactment of the Collection and Code of laws put a cornerstone to the science of Russian jurisprudence, however, this did not create the science yet.

Russian lawyers saw the mission of the criminal law science in comprehension of essence of criminal laws, the process of law making, value of criminal laws in the life of people during this or that era. The works of those years advanced the idea that the criminal law science should not be limited to the criminal law research of "regulations of positive laws"; it should study "those main beginnings which form the basis for criminal laws". It was noted that the science of criminal law should consider the concepts and institutions of criminal law as historical changeable categories. The conclusion was drawn that scientific knowledge of criminal law involves three aspects: a dogmatic, historical, and philosophical one.

Eventually, by the end of the mid-19th century the Russian lawyers had a concept of the science of criminal jurisprudence as the science studying social and moral causality of criminal law bans, criminal laws of the state, their practical application, foreign criminal legislation, its application, foreign criminal law science. Lawyers of that time did not question the provision that the science of criminal law should consider criminal legislation as a dynamic system formation; explore the essence of crimes, explain the need and fairness of criminal punishments.

At the same time the works covered the idea (in some works it was done in general, in others more or less extensively) that the science of criminal law could not be limited to the studying of legal constructions of certain concepts, studying of criminal action and punishment as abstract categories, distracted from realities; it should investigate them as the vital phenomena. While studying the practice of application of Russian criminal laws, foreign criminal legislation and the science of criminal law should facilitate the proper construction of criminal legislation of Russia. It is necessary to notice that the same ideas lie in the core of a modern view of the Russian criminal law science.

\section{References}

1. Solntsev, G.I. (1907) Rossiyskoe ugolovnoe pravo [Russian Criminal Law]. Kazan: [s.n.].

2. Goreglyad, G. (1815) Opyt nachertaniya rossiyskogo ugolovnogo prava [Experience of formation of Russian criminal law]. St. Petersburg: I. Ioanessov. 
3. Gulyaev, P. (1833) Rossiyskoe ugolovnoe pravo, sostavlennoe iz gosudarstvennykh zakonov [Russian criminal law composed of state laws]. St. Petersburg: Department of Foreighn Trade.

4. Neyman, I. (1814) Nachal'nye osnovaniya ugolovnogo prava [Initial grounds for criminal law]. St. Petersburg: I. Ioanessov.

5. Naumov, I. (1813) Razdelenie prestupleniy protiv prava grazhdanskogo i protiv prava ugolovnogo [Separation of crimes against civil and criminal law]. St. Petersburg: [s.n.].

6. Bogorodsky, S. (1835) Polozheniya, izvlechennye iz razsuzhdeniya o filosofii ugolovnykh zakonov u drevnikh i novykh narodov, kotorye s odobreniya yuridicheskogo fakul'teta imperatorskogo S.-Peterburgskogo universiteta zashchishchal publichno, dlya polucheniya stepeni doktora zakonovedeniya Savva Bogorodskiy [The provisions extracted from the discourse on the philosophy of criminal laws from ancient and new peoples, which, with the approval of the law faculty of St. Petersburg Imperial University, Savva Bogorodsky defended publicly to obtain the degree of a doctorate in jurisprudence]. St. Peterburg: [s.n.].

7. Danilovich, I. (1837) O khode ugolovnogo zakonovedeniya voobshche i preimushchestvenno v Germanii [On criminal law in general and mainly in Germany]. Zhurnal ministerstva narodnogo prosveshcheniya. 14. pp. 340-341.

8. Gordeenko, G. (1838) V chem dolzhno sostoyat' uchenoe ugolovnoe zakonovedenie $v$ Rossii $v$ nastoyashchee vremya [What should the scientific criminal law in Russia at the present time consist of]. Law Dr. Diss. Kharkiv.

9. Radishchev, A.N. (1952) Izbrannye filosofskie $i$ obshchestvenno-politicheskie proizvedeniya [Selected Philosophical and Socio-Political Works]. Moscow: Gospolitizdat. pp. $459-460$.

10. Feldstein, G.S. (2003) Glavnye techeniya v istorii nauki ugolovnogo prava v Rossii [The main trends in the history of criminal law in Russia]. Mosow: Zertsalo.

11. Barshev, Ya. (1846) O vliyanii obychaya, praktiki, zakonodatel'stva i nauki na razvitie ugolovnogo, v osobennosti russkogo, prava: rech', proiznesennaya v torzhestvennom sobranii impe-ratorskogo Sankt-Peterburgskogo universiteta ordinarnym professorom, doktorom prav Yakovom Barshevym fevralya 8 dnya 1846 goda [On the influence of custom, practice, legislation and science on the development of criminal law, especially Russian law: a speech delivered at the ceremonial meeting of the Imperial St. Petersburg University by an ordinary professor, Doctor of Law Yakov Barshev on February 8, 1846]. [s.1., s.n.]

12. Barshev, S.I. (n.d.) Vzglyad na nauku ugolovnogo zakonovedeniya [A look at the science of criminal law]. [s.l., s.n.]. 